\title{
Maternal risk for Down syndrome is modulated by genes involved in folate metabolism
}

\author{
Bruna Lancia Zampieri ${ }^{\mathrm{a}}$, Joice Matos Biselli ${ }^{\mathrm{a}}$, Eny Maria Goloni-Bertollo ${ }^{\mathrm{a}}$, Hélio Vannucchi ${ }^{\mathrm{b}}$, \\ Valdemir Melechco Carvalho ${ }^{\mathrm{c}}$, José Antônio Cordeiro ${ }^{\mathrm{d}}$ and Érika Cristina Pavarino ${ }^{\mathrm{a}, *}$ \\ ${ }^{a}$ Unidade de Pesquisa em Genética e Biologia Molecular (UPGEM), Faculdade de Medicina de São José do Rio \\ Preto (FAMERP), São José do Rio Preto, São Paulo, Brazil \\ ${ }^{\mathrm{b}}$ Faculdade de Medicina de Ribeirão (USP), Ribeirão Preto, São Paulo, Brazil \\ ${ }^{\mathrm{c}}$ Fleury, Centro de Medicina Diagnóstica, São Paulo, São Paulo, Brazil \\ ${ }^{\mathrm{d}}$ Departamento de Epidemiologia e Saúde Coletiva da Faculdade de Medicina de São José do Rio Preto \\ (FAMERP), São José do Rio Preto, São Paulo, Brazil
}

\begin{abstract}
Studies have shown that the maternal risk for Down syndrome (DS) may be modulated by alterations in folate metabolism. The aim of this study was to evaluate the influence of 12 genetic polymorphisms involved in folate metabolism on maternal risk for DS. In addition, we evaluated the impact of these polymorphisms on serum folate and plasma methylmalonic acid (MMA, an indicator of vitamin $\mathrm{B}_{12}$ status) concentrations. The polymorphisms transcobalamin II (TCN2) c.776C $>\mathrm{G}$, betainehomocysteine S-methyltransferase $(B H M T) \mathrm{c} .742 \mathrm{~A}>\mathrm{G}$, methylenetetrahydrofolate reductase $(N A D(P) H)(M T H F R) \mathrm{c} .677 \mathrm{C}>\mathrm{T}$ and the MTHFR 677C-1298A-1317T haplotype modulate DS risk. The polymorphisms MTHFR c.677C $>\mathrm{T}$ and solute carrier family 19 (folate transporter), member 1 (SLC19A1) c.80 A>G modulate folate concentrations, whereas the 5-methyltetrahydrofolatehomocysteine methyltransferase reductase $(M T R R) \mathrm{c} .66 \mathrm{~A}>\mathrm{G}$ polymorphism affects the MMA concentration. These results are consistent with the modulation of the maternal risk for DS by these polymorphisms.
\end{abstract}

Keywords: Down syndrome, genetic polymorphism, folate metabolism

\section{Introduction}

Down syndrome (DS), or trisomy 21 (MIM 190685), is the most common genetic disorder with a prevalence of 1 in 660 live births [27]. The only well-established risk factor for DS is advanced maternal age [7]. However, many DS children are born to mothers younger than 35 years, suggesting that other factors can also influence DS etiology. James et al. [48] hypothesized that pericentromeric hypomethylation, result-

* Address for correspondence: Profa. Dra. Érika Cristina Pavarino, UPGEM, FAMERP (Bloco U6), Av. Brigadeiro Faria Lima, n. ${ }^{\circ}$ 5416, São José do Rio Preto - SP, Brazil, CEP: 15.090-000. Tel.: +55 173201 5720; E-mail: erika@famerp.br. ing from impaired folate metabolism secondary to a polymorphism on methylenetetrahydrofolate reductase $(N A D(P) H)(M T H F R)$ gene, could impair chromosomal segregation and increase the risk for chromosome 21 nondisjunction in young mothers. Since then, several studies have revealed that polymorphisms in genes involved in the folate pathway modulate the maternal risk for DS $[6,17,35,39,49]$ and the concentrations of metabolites involved in the folate pathway [14,30,43].

Folate metabolism vitally participates in the biosynthesis of nucleotides and S-adenosyl-methionine (SAM), the major methyl donor for DNA methylation reactions (Fig. 1). A folate deficiency has been associated with DNA hypomethylation, DNA damage, chromosomal instability, abnormal chromosome segregation and aneuploidy of chromosome $21[45,47]$. 
This study aimed to evaluate associations between 12 genetic polymorphisms, MTHFR c.677C $>\mathrm{T}$, MTHFR c.1298A >C, MTHFR c.1317T>C, 5-methyltetrahydrofolate-homocysteine methyltransferase (MTR) c.2756 $\mathrm{A}>\mathrm{G}$, 5-methyltetrahydrofolate-homocysteine methyltransferase reductase $(M T R R)$ c.66A $>\mathrm{G}$, cystathioninebeta-synthase $(C B S)$ c.844ins68, CBS c.833T >C, solute carrier family 19 (folate transporter), member 1 (SLC19A1, also known as reduced folate carrier - RFC1) c.80A > G, transcobalamin II (TCN2) c.776C $>\mathrm{G}$, TCN2 c.67A $>\mathrm{G}$, methylenetetrahydrofolate dehydrogenase (NADP+ dependent) 1, methenyltetrahydrofolate cyclohydrolase, formyltetrahydrofolate synthetase (MTHFD1) c.1958G >A and betainehomocysteine S-methyltransferase (BHMT) c.742G >A, and the maternal risk for DS. In addition, we evaluated the impact of the polymorphisms on serum folate and plasma methylmalonic acid (MMA, an indicator of the vitamin $\mathrm{B}_{12}$ status) concentrations.

\section{Material and methods}

The study protocol was approved by the Research Ethics Committee of São José do Rio Preto Medical School (CEP-FAMERP), State of São Paulo, and by the National Research Commission (CONEP), Brazil. Fasting peripheral blood samples were obtained from 105 women (case mothers) with karyotypically confirmed full trisomy 21 (translocation or mosaicism were not included) liveborn offspring and from 185 mothers with at least one healthy offspring and no history of miscarriage (control mothers). Case mothers were identified at the time of their offspring's initial consultation at the General Genetics Outpatient Service of Hospital de Base de São José do Rio Preto, SP, Brazil, and were enrolled in the study during the following consultation. The control group was composed of volunteers from the FAMERP Campus and of women submitted to routine exams at the Clinical Analysis Laboratory of Hospital de Base de São José do Rio Preto. Informed consent was obtained from all study participants.

The maternal age of the case group was calculated using the age of the mothers at the birth of the DS child and using the age of the mothers at the birth of the last child for the control group. The median child age at the time of the mother's recruitment was 14.8 years $(0.15-$ $39.09)$ for the control group and 1.1 years (0.02-30.35) for the case group. Given that the Brazilian population is ethnically heterogeneous, a result of centuries of admixture in the immigrant population, separating it into distinct ethnic groups becomes a challenge. This process of admixture has contributed to the specific characteristics of the Brazilian population [12]. All participants were from the same region of São Paulo (in the northwest). Thus, they likely share similar sociodemographic characteristics and racial backgrounds.

Genomic DNA was isolated from leucocytes in peripheral blood according to Miller et al. [46] or using the $G F X^{\mathrm{TM}}$ Genomic Blood DNA Purification Kit (GE Healthcare, USA). The polymorphisms MTHFR c.677C $>$ T, MTR c.2756A $>\mathrm{G}$, SLC19A1 c.80A >G, TCN2 c.776C >G, $C B S$ c.844ins68, $C B S$ c. $833 \mathrm{~T}>\mathrm{C}$ and $M T H F D 1$ c. $1958 \mathrm{G}>\mathrm{A}$ were determined as previously described $[11,17,23,33,41]$. The variant $T C N 2$ c. $776 \mathrm{C}>\mathrm{G}$ was analyzed via the polymerase chain reaction-restriction fragment length polymorphism (PCR-RFLP) method using primers from Pietrzyk \& Bik-Multanowski (2003) [20], and the PCR products were digested with the Scrfl enzyme. The polymorphisms MTRR c.66A $>\mathrm{G}, T C N 2$ c.67A $>\mathrm{G}$ and BHMT c.742G $>\mathrm{A}$ were analyzed by real time PCR allelic discrimination (Taqman SNP Genotyping Assays, C__3068176_10, C__25967461_10 and C__11646606_20 respectively, Applied Biosystems, Foster City, CA, USA). Automated sequencing was used to investigate the MTHFR c. $1298 \mathrm{~A}>\mathrm{C}$ and c. $1317 \mathrm{~T}>\mathrm{C}$ polymorphisms as previously described [37]. The analysis, except for the purification procedure, was performed using the enzymes Exonuclease $I$ and Shrimp Alkaline Phosphatase (Fermentas Life Sciences, Brazil) according to the manufacturer's instructions. Plasma MMA concentrations were determined by liquid chromatography-tandem mass spectrometry as previously described [51], and folate concentrations were determined by chemiluminescence (Immulite Kit, DPC Medlab, Brazil).

\subsection{Statistical analysis}

The Hardy-Weinberg (HW) equilibrium was assessed via a chi-square test using the BioEstat program, and the genotype frequencies were compared between case and control mothers by the likelihood ratio test. The relationship between the number of deleterious alleles for the 12 loci tested and the maternal risk for DS was assessed by logistic regression analysis. For this analysis, the sample was divided in two subsets (0-7 and 8-14 alleles for the total group and for the subgroup of women with maternal age $\leqslant 35$ years old) according to the median value of deleterious alleles (median $=$ 7). Previously published data $[2,9,16]$ and the results in 
Table 1

Deleterious alleles considered for each of the 12 genetic polymorphisms investigated

\begin{tabular}{lc}
\hline Polymorphism & Allele deleterious \\
\hline$M T H F R$ c. $677 \mathrm{C}>\mathrm{T}$ & $\mathrm{T}$ \\
$M T H F R$ c. $1298 \mathrm{~A}>\mathrm{C}$ & $\mathrm{C}$ \\
$M T H F R$ c. $1317 \mathrm{~T}>\mathrm{C}$ & $\mathrm{C}$ \\
$M T R$ c. $2756 \mathrm{~A}>\mathrm{G}$ & $\mathrm{G}$ \\
$M T R R$ c. $66 \mathrm{~A}>\mathrm{G}$ & $\mathrm{G}$ \\
$S L C 19 A 1$ c. $80 \mathrm{~A}>\mathrm{G}$ & $\mathrm{G}$ \\
$T C N 2$ c. $67 \mathrm{~A}>\mathrm{G}$ & $\mathrm{G}$ \\
$T C N 2$ c. $776 \mathrm{C}>\mathrm{G}$ & $\mathrm{G}$ \\
$C B S$ c. 844 ins 68 & $\mathrm{I}^{*}$ \\
$C B S$ c. $833 \mathrm{~T}>\mathrm{C}$ & $\mathrm{C}$ \\
$M T H F D 1$ c. $1958 \mathrm{G}>\mathrm{A}$ & $\mathrm{A}$ \\
BHMT $\mathrm{c} .742 \mathrm{G}>\mathrm{A}$ & $\mathrm{G}$ \\
\hline
\end{tabular}

* The results of the CBS c. 844ins68 genotypes were defined as I for the allele with the $68 \mathrm{bp}$ insertion and $\mathrm{W}$ for the wild - type allele.

this study were used to assess the deleterious status of both alleles for each polymorphism, shown in Table 1 . The haplotype frequencies of the MTHFR, TCN2 and $C B S$ genes were inferred using the Haploview program (version 4.0).

Multiple logistic regression analyses, with forward stepwise selection by the likelihood ratio, were performed using SPSS19 software. Genotype data for the 12 polymorphisms, maternal age and folate and MMA concentrations were included in the original models to verify the influence of each of these factors on the maternal risk for DS. Only the women that provided all the data were included in this analysis. The genotype data used in the logistic regression model was analyzed in two different ways: considering either (1) the dominant model (heterozygous + mutant homozygous versus wild-type homozygous) or (2) the recessive model (wild-type homozygous + heterozygous versus mutant homozygous). Once advanced maternal age is shown to be an important risk factor for DS, the analyses were also performed in a sub-group formed only by women $\leqslant 35$ years old (case: 54; control:173). These tests were applied to generate an odds ratio (OR) and $95 \%$ confidence intervals $(\mathrm{CI})$.

Stepwise forward multivariate logistic regression analyses were also performed for the total group (case and control together) to verify the factors that influence biochemical parameters. For MMA analysis, the concentrations were categorized considering the values above (case mothers $=21$; control mothers $=41$ ) or equal to/below (case mothers $=66$; control mothers $=$ 137) the $75^{\text {th }}$ percentile, and the genotype data for the 12 polymorphisms (recessive and dominant models) as well as the folate concentrations were used as predictors. For folate analysis, the concentrations were cate-
Table 2

Genotype frequencies of the 12 polymorphisms involved in the folate pathway in DS and control mothers

\begin{tabular}{|c|c|c|c|c|c|c|}
\hline \multirow[b]{2}{*}{ Polymorphism } & \multicolumn{3}{|c|}{ DS mothers } & \multicolumn{3}{|c|}{ Control mothers } \\
\hline & Genotype & $\mathrm{N}$ & $\%$ & $\mathbf{N}$ & $\%$ & $\mathrm{P}^{\mathrm{a}}$ \\
\hline \multirow[t]{3}{*}{ MTHFR c. $677 \mathrm{C}>\mathrm{T}$} & $\mathrm{CC}$ & 40 & 38.1 & 94 & 50.8 & 0.09 \\
\hline & CT & 55 & 52.4 & 73 & 39.5 & \\
\hline & TT & 10 & 9.5 & 18 & 9.7 & \\
\hline \multirow[t]{3}{*}{ MTHFR c. $1298 \mathrm{~A}>\mathrm{C}$} & AA & 51 & 48.6 & 101 & 55.2 & 0.56 \\
\hline & $\mathrm{AC}$ & 48 & 45.7 & 73 & 39.9 & \\
\hline & $\mathrm{CC}$ & 6 & 5.7 & 9 & 4.9 & \\
\hline \multirow[t]{3}{*}{ MTHFR c. $1317 \mathrm{~T}>\mathrm{C}$} & TT & 89 & 84.8 & 158 & 86.3 & 0.55 \\
\hline & $\mathrm{TC}$ & 16 & 15.2 & 23 & 12.6 & \\
\hline & $\mathrm{CC}$ & 0 & 0 & 2 & 1.1 & \\
\hline \multirow[t]{3}{*}{ MTRc. $2756 \mathrm{~A}>\mathrm{G}$} & AA & 62 & 59.1 & 127 & 68.7 & 0.22 \\
\hline & AG & 38 & 36.2 & 49 & 26.5 & \\
\hline & GG & 5 & 4.8 & 9 & 4.9 & \\
\hline \multirow[t]{3}{*}{$M T R R$ c. $66 \mathrm{~A}>\mathrm{G}$} & $\mathrm{AA}$ & 36 & 34.3 & 65 & 35.1 & 0.91 \\
\hline & AG & 53 & 50.5 & 89 & 48.1 & \\
\hline & GG & 16 & 15.2 & 31 & 16.8 & \\
\hline \multirow[t]{3}{*}{$S L C 19 A 1 \mathrm{c} .80 \mathrm{~A}>\mathrm{G}$} & $\mathrm{AA}$ & 29 & 27.6 & 53 & 28.7 & 0.86 \\
\hline & AG & 48 & 45.7 & 88 & 47.6 & \\
\hline & GG & 28 & 26.7 & 44 & 23.8 & \\
\hline \multirow[t]{3}{*}{$C B S$ c $.833 \mathrm{~T}>\mathrm{C}$} & TT & 83 & 79.1 & 145 & 78.4 & 0.26 \\
\hline & $\mathrm{TC}$ & 18 & 17.1 & 38 & 20.5 & \\
\hline & $\mathrm{CC}$ & 4 & 3.8 & 2 & 1.1 & \\
\hline \multirow[t]{3}{*}{$C B S$ c.844ins68* } & WW & 83 & 79.1 & 145 & 78.4 & 0.26 \\
\hline & WI & 18 & 17.1 & 38 & 20.5 & \\
\hline & II & 4 & 3.8 & 2 & 1.1 & \\
\hline \multirow[t]{3}{*}{$T C N 2$ c. $67 \mathrm{~A}>\mathrm{G}$} & AA & 77 & 73.3 & 129 & 69.7 & 0.60 \\
\hline & $\mathrm{AG}$ & 26 & 24.8 & 49 & 26.5 & \\
\hline & GG & 2 & 1.9 & 7 & 3.8 & \\
\hline \multirow[t]{3}{*}{ TCN2c.776C $>\mathrm{G}$} & $\mathrm{CC}$ & 42 & 40.0 & 75 & 40.5 & 0.19 \\
\hline & $\mathrm{CG}$ & 46 & 43.8 & 93 & 50.3 & \\
\hline & GG & 17 & 16.2 & 17 & 9.2 & \\
\hline \multirow[t]{3}{*}{ BHMT c. $742 \mathrm{G}>\mathrm{A}$} & GG & 56 & 53.3 & 77 & 41.6 & 0.10 \\
\hline & GA & 43 & 41.0 & 88 & 47.6 & \\
\hline & $\mathrm{AA}$ & 6 & 5.7 & 20 & 10.8 & \\
\hline \multirow[t]{3}{*}{ MTHFD1 c. $1958 \mathrm{G}>\mathrm{A}$} & GG & 34 & 32.4 & 72 & 38.9 & 0.16 \\
\hline & GA & 58 & 55.2 & 81 & 43.8 & \\
\hline & $\mathrm{AA}$ & 13 & 12.4 & 32 & 17.3 & \\
\hline
\end{tabular}

${ }^{\mathrm{a}}$ Likelihood Ratio Chi-Square test for genotypes.

*The results of the CBS c.844ins68 genotypes were defined as $W$ for the wild-type allele and I for the allele with the $68 \mathrm{bp}$ insertion.

gorized considering values below (case mothers $=21$; control mothers $=44$ ) or equal to/above (case mothers $=66$; control mothers $=137$ ) the $25^{\text {th }}$ percentile, and the genotype data for the 12 polymorphisms (recessive and dominant models) as well as the MMA concentrations were used as predictors.

The computer-assisted statistical analyses were carried out using Minitab for Windows program (Release 14) and SPSS19 software. Values of $P \leqslant 0.05$ were considered significant.

\section{Results}

According to the likelihood ratio test, the genotype 
Table 3

Haplotype frequencies of the MTHFR, TCN2 and CBS genes in case and control groups

\begin{tabular}{lcccc}
\hline Haplotypes & Case & Control & $\mathrm{X}^{2}$ & $\mathrm{P}$ \\
\hline MTHFR 677 / 1298 / 1317 & & & & \\
C / A / T & 0.281 & 0.385 & 6.40 & 0.01 \\
T / A / T & 0.357 & 0.292 & 2.59 & 0.11 \\
C / C / T & 0.286 & 0.249 & 0.95 & 0.33 \\
C / A / C & 0.076 & 0.074 & 0.01 & 0.92 \\
TCN2 67 / 776 & & & & \\
A / C & 0.496 & 0.508 & 0.08 & 0.78 \\
A / G & 0.361 & 0.322 & 0.92 & 0.34 \\
G / C & 0.123 & 0.149 & 0.75 & 0.39 \\
G / G & 0.020 & 0.022 & 0.02 & 0.90 \\
CBS 833 / 844 & & & & \\
T / W & 0.876 & 0.886 & 0.14 & 0.71 \\
C / I & 0.124 & 0.114 & 0.14 & 0.71 \\
T / I & 0 & 0 & - & - \\
C / W & 0 & 0 & - & - \\
\hline
\end{tabular}

frequencies were not different between DS and control mothers (Table 2). The genotype frequencies were in HW equilibrium in both groups, except for the polymorphisms $C B S$ c.833T $>C$ and c.844ins68 $(\mathrm{P}=0.032$ for both polymorphisms), and a Bonferroni adjustment revealed that the variant homozygous genotypes were more frequent in the case group $(\mathrm{P}<0.0005$ for both polymorphisms). The median value of the folate concentration in DS mothers $(12.2 \mathrm{ng} / \mathrm{mL}, 3.7-36.5)$ was significantly lower $(\mathrm{P}=0.028)$ than in the case group (14.6 ng/mL; 5-74). Conversely, the median value of the MMA concentration in DS mothers $(0.17 \mu \mathrm{mol} / \mathrm{L}$, $0.07-1.46)$ was significantly higher $(\mathrm{P}=0.003)$ that in the control group $(0.14 \mu \mathrm{mol} / \mathrm{L}, 0.05-0.81)$.

The haplotype frequencies of the MTHFR, TCN2 and $C B S$ genes are presented in Table 3. The MTHFR gene exhibited linkage disequilibrium (LD) between the polymorphisms c.677C $>$ T and c. $1298 \mathrm{~A}>\mathrm{C}$ (LOD $\left.=11.05 ; \mathrm{D}^{\prime}=1.0\right), \mathrm{c} .677 \mathrm{C}>\mathrm{T}$ and c. $1317 \mathrm{~T}>\mathrm{C}(\mathrm{LOD}=$ 3.23 ; D' $=1.0$ ) and c. $1298 \mathrm{~A}>\mathrm{C}$ and c. $1317 \mathrm{~T}>\mathrm{C}$ (LOD $=3.83$; D' $=1.0)$. A significantly higher frequency of the C-A-T haplotype (wild-type alleles) was observed in the control group compared to the case group $(\mathrm{P}=0.01)$. The TCN2 polymorphisms c.67A $>\mathrm{G}$ and c.776C $>\mathrm{G}$ are weakly linked $\left(\mathrm{LOD}=2.46\right.$; $\mathrm{D}^{\prime}=0.63$ ), whereas the $C B S$ variants at positions 833 and 844 are strongly linked (LOD $=74.17$; D' $=1.0$ ). There was no difference in the haplotype frequencies for the TCN2 and $C B S$ genes between the groups. The $C B S$ haplotypes $833 \mathrm{~T} / 844 \mathrm{I}$ and $833 \mathrm{C} / 844 \mathrm{~W}$ were not present in either group.

When considering the dominant model using logistic stepwise regression analysis, maternal age (OR, 1.12; 95\% CI, 1.075-1.174; $P<0.0005)$ and the MTHFR
Table 4

Variables associated with DS risk according to the multiple logistic regression analyses with forward stepwise selection

\begin{tabular}{|c|c|c|c|}
\hline & OR & $95 \% \mathrm{CI}$ & $\mathrm{P}$ value* \\
\hline \multicolumn{4}{|l|}{ Total Group } \\
\hline \multicolumn{4}{|l|}{ Dominant Model } \\
\hline Maternal age (years) & 1.12 & $1.075-1.174$ & $<0.0005$ \\
\hline \multicolumn{4}{|l|}{ MTHFR c. $677 \mathrm{C}>\mathrm{T}$} \\
\hline $\mathrm{CC}$ & & 1.00 (reference) & \\
\hline CT or TT & 1.76 & $1.011-3.073$ & 0.04 \\
\hline \multicolumn{4}{|l|}{ Recessive Model } \\
\hline Maternal Age & 1.13 & $1.080-1.183$ & 0.0005 \\
\hline \multicolumn{4}{|l|}{$T C N 2$ с. $776 \mathrm{C}>\mathrm{G}$} \\
\hline $\mathrm{CC}$ or $\mathrm{CG}$ & & 1.00 (reference) & \\
\hline GG & 2.45 & $1.038-5.788$ & 0.04 \\
\hline \multicolumn{4}{|l|}{ BHMT c. $742 \mathrm{G}>\mathrm{A}$} \\
\hline GG or GA & & 1.00 (reference) & \\
\hline AA & 0.26 & $0.078-0.843$ & 0.02 \\
\hline \multicolumn{4}{|c|}{ Mothers aged $\leqslant 35$ years } \\
\hline \multicolumn{4}{|c|}{ Dominant Model } \\
\hline Maternal age (years) & 1.21 & $1.098-1.321$ & $<0.0005$ \\
\hline \multicolumn{4}{|l|}{ MTHFR c. $677 \mathrm{C}>\mathrm{T}$} \\
\hline $\mathrm{CC}$ & & 1.00 (reference) & \\
\hline CT or TT & 2.30 & $1.135-4.661$ & 0.02 \\
\hline \multicolumn{4}{|l|}{ Recessive Model } \\
\hline \multicolumn{4}{|l|}{ TCN2 c. $776 \mathrm{C}>\mathrm{G}$} \\
\hline $\mathrm{CC}$ or $\mathrm{CG}$ & & 1.00 (reference) & \\
\hline GG & 3.47 & $1.353-8.917$ & 0.01 \\
\hline \multicolumn{4}{|l|}{ BHMT c. $742 \mathrm{G}>\mathrm{A}$} \\
\hline GG or GA & & 1.00 (reference) & \\
\hline AA & 0.12 & $0.015-0.974$ & 0.05 \\
\hline
\end{tabular}

OR. odds ratio; CI. confidence interval.

${ }^{*} \mathrm{P}$ - Results of the stepwise forward multivariate logistic regression analysis to identify independent risk factors for having a child with Down syndrome risk. The following regressors were used: maternal age, data from the 12 polymorphism, MMA and folate.

c.677 CT or TT genotypes (OR, 1.76; 95\% CI, 1.011$3.073 ; P=0.04)$ significantly contributed independently to DS risk. Maternal age (OR, 1.13; 95\% CI, 1.080-1.183; $P<0.0005)$ and the TCN2 c.776 GG (OR, 2.45; 95\% CI, 1.038-5.788; $P=0.04)$ and BHMT c.742 AA genotypes (OR, 0.26; 95\% CI, 0.078-0.843; $P=0.02$ ) were significant modifiers of DS risk under the recessive model (Table 4 ).

With respect to the factors that exert influence on biochemical parameters, folate concentrations below the $25^{\text {th }}$ percentile were associated with the presence of MTHFR c.677 CT or TT (OR, 2.19; 95\% CI, 1.2233.920; $P=0.01$ ), whereas MMA concentrations above the $75^{\text {th }}$ percentile were associated with the MTRR c.66 AG or GG genotypes (OR, 1.98; 95\% CI, 1.122-3.495; $P=0.02$ ), both in the dominant model (Table 5).

When we analyzed only women $\leqslant 35$ years old at conception, the most predictive independent risk factors for DS were maternal age (OR, 1.21; 95\% CI, $1.098-1.321 ; P<0.0005)$ and the MTHFR c.677 CT or TT genotypes (OR, 2.30; 95\% CI, 1.135-4.661; $P=$ 
Table 5

Variables associated with folate and methylmalonic acid (MMA) concentration according to the multiple logistic regression analyses with forward stepwise selection

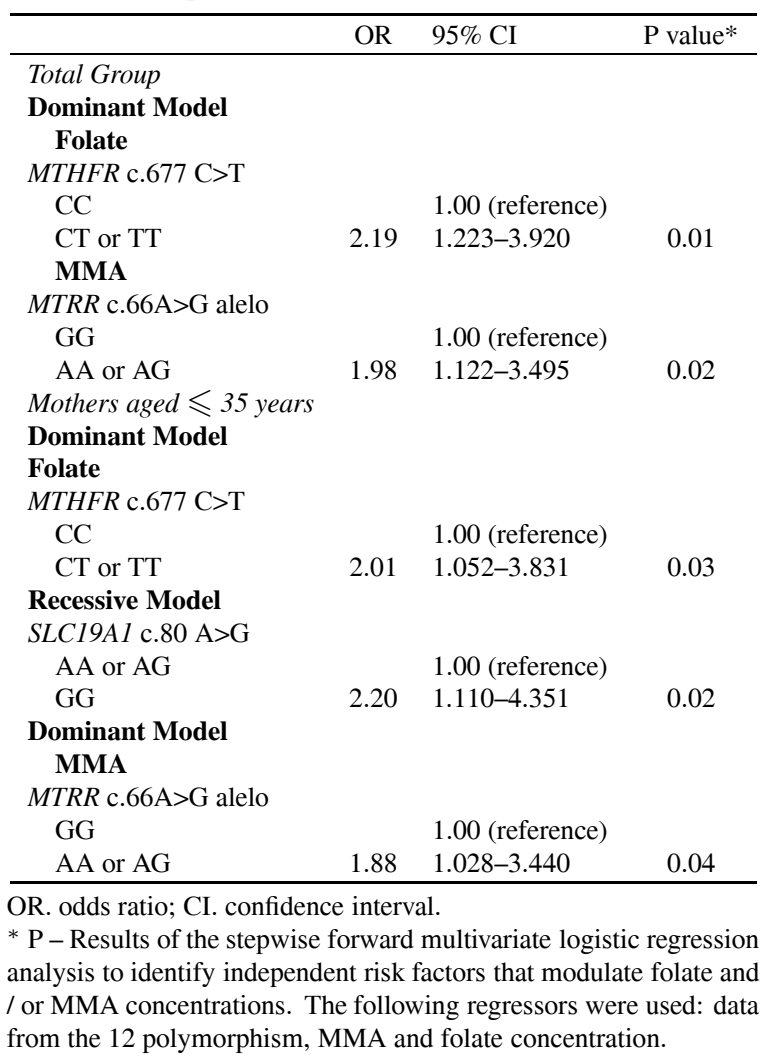

$0.02)$ in the dominant model and the TCN2 c.776 GG (OR, 3.47; 95\% CI, 1.353-8.917; $P=0.01$ ) and $B H M T$ c.742 AA genotypes (OR, 0.12; 95\% CI, 0.015-0.974; $P=0.05)$ in the recessive model (Table 4).

In women $\leqslant 35$ years old, folate concentrations below the $25^{\text {th }}$ percentile were associated with the presence of MTHFR c.677 CT or TT (OR, 2.01; 95\% CI, $1.052-3.831 ; P=0.03)$ in the dominant model and with the presence of SLC19A I c.80 GG (OR, 2.20; 95\% CI, $1.110-4.351 ; P=0.02)$ in the recessive model. The presence of MTRR c.66 AG or GG were associated with MMA concentrations above the $75^{\text {th }}$ percentile (OR, 1.88; 95\%CI, 1.028-3.440; $P=0.04$ ) in the dominant model (Table 5).

The median number of deleterious alleles did not differ between the groups, both in the total group and in the group of women $\leqslant 35$ years old.

\section{Discussion}

Although advanced maternal age at conception represents an important and well-established risk factor for
DS [7], as confirmed in this study, the occurrence of DS births by young mothers suggests that other risk factors are also involved in the etiology of this syndrome. Abnormal folate metabolism has been identified as a maternal risk factor for DS in several populations [9]. This study reveals that polymorphisms in folate metabolism genes modulate the maternal risk for bearing a child with DS. This is the first study evaluating the role of MTHFR c. $1317 \mathrm{~T}>\mathrm{C}, C B S$ c. $833 \mathrm{~T}>\mathrm{C}, T C N 2$ c. $67 \mathrm{~A}>\mathrm{G}$, $M T H F D 1$ c. $1958 \mathrm{G}>\mathrm{A}$ and $B H M T$ c. $742 \mathrm{G}>\mathrm{A}$ polymorphisms in mothers of DS children in a Brazilian population. In addition, the influence of the polymorphisms BHMT c. $742 \mathrm{G}>\mathrm{A}$ and $T C N 2 \mathrm{c} .67 \mathrm{~A}>\mathrm{G}$ on $\mathrm{DS}$ risk have never been studied until now.

The polymorphism $T C N 2$ c. 776 GG, which has been previously investigated for DS risk by our group in a smaller sample [21] and by Fintelman-Rodrigues et al. [38], with negative results, was associated with increased DS risk in this study. Moreover, we observed that the TCN2 c.776 GG genotype influenced the risk for DS in both the total group and in the group with the conception age of women $\leqslant 35$ years. The presence of the TCN2 c.776 GG genotype has been shown to negatively affect the serum concentration of the TCN2 protein-vitamin $\mathrm{B}_{12}$ complex [28] and to be associated with low concentrations of SAM in childbearingage women [43]. Considering that SAM is the major methyl donor for DNA methylation reactions, the variant $T C N 2$ c. $776 \mathrm{C}>\mathrm{G}$ may influence maternal risk for DS by modifying the DNA methylation pattern. We are the first group to study the influence of the TCN2 c.67A $>$ G polymorphism on maternal risk for $D S$, where no association was observed with DS risk. The LD between the variants $T C N 2$ c. $67 \mathrm{~A}>\mathrm{G}$ and c. $776 \mathrm{C}>\mathrm{G}$ observed in this study is consistent with a previous study [26].

Our group is the first to evaluate the role of the BHMT c. $742 \mathrm{G}>$ A polymorphism on the risk of bearing a DS child, where an association between the $B H M T$ c.742 AA genotype and decreased maternal risk for DS was observed. The BHMT protein catalyzes an alternative route of homocysteine (Hcy) remethylation (Fig. 1). The polymorphism produces two distinct alloenzymes, which exhibit significant differences in $\mathrm{Km}$ values for Hcy and betaine [10]. The $K m$ values are lower for the variant alloenzyme compared to the wildtype. The low $K m$ of the alloenzyme may be responsible for the increased efficiency of Hcy remethylation using betaine as a methyl group donor [42]. The decreased effect of the BHMT c.742A allele on DS risk could be expected when the maternal AA genotype 
was protective against neural tube defects (NTD) in the offspring [2,16]. Moreover, NTDs and DS are influenced by the same genetic factors involved in folate metabolism [13].

Polymorphisms in the MTHFR gene have been extensively analyzed for influences on folate and methyl metabolisms in maternal risk for DS. The MTHFR enzyme plays an important role in regulating DNA methylation reactions through the reduction of 5,10-methylentetrahydrofolate $(5,10-\mathrm{MTHF})$ to 5methylTHF (Fig. 1). A common polymorphism in the MTHFR gene, c.677 $\mathrm{C}>\mathrm{T}$, is known to decrease the affinity of the enzyme for its flavin adenine dinucleotide (FAD) cofactor, thereby decreasing the enzyme activity [4,25]. The heterozygous MTHFR c.677 CT genotype reduces the enzyme activity by approximately $35 \%$, and the homozygous TT genotype reduces activity by $70 \%$ [41]. In this study, the presence of the MTHFR c.677 CT or TT genotypes was associated with increased maternal risk for DS, which corroborates previous associations between the MTHFR c.677 C>T polymorphism and the modulation of the maternal risk for DS $[32,39,49]$. Coppedè et al. [8] have observed an association between the MTHFR c.677 T allele and the occurrence of chromosome damage and missegregation events in mothers of DS individuals, supporting the role of this allele in the etiology of trisomy 21 . Previously, these authors observed a significant increase in the rate of aneuploidy of chromosome 21 in these mothers [31].

The LD between the MTHFR polymorphisms c. $677 \mathrm{C}>\mathrm{T}$, c. $1298 \mathrm{~A}>\mathrm{C}$ and c.1317T $>\mathrm{C}$ observed in this study is consistent with the literature, which has illustrated LD between the MTHFR c.677 C>T and c.1298A >C $[9,34]$. Moreover, the silent polymorphism at position 1317 is near the one at 1298 position. The higher frequency of the MTHFR 677C-1298A-1317T haplotype in the control group confirms the protective maternal effect of these alleles against DS, which is indicated by the rare alleles $677 \mathrm{~T}$ and $1298 \mathrm{C}$ that have been associated with increased maternal risk for DS in several studies $[22,32,39,49]$. In addition, this result corroborates the association between the 677T-1298C haplotype and the maternal risk for DS observed by Scala et al. [17].

MTRR, an enzyme codified by the MTRR gene, is responsible for the maintenance of the activated form of the MTR enzyme [29]. Several studies have observed an association between the MTRR c.66A $>\mathrm{G}$ polymorphism, alone and combined with other genetic variants, and DS risk and an elevated Hcy concentration [3,
$5,6,36,40,44,49]$. Additionally, a steady state kinetic analysis revealed a significant decrease in the affinity for MTRR accompanying a c.66A $>\mathrm{G}$ substitution, revealing a significant difference in the relative efficacies of the common MTRR polymorphism c.66A $>\mathrm{G}$ [15]. These findings further validate the association between the MTRR c.66 AG and GG genotypes and higher concentrations of MMA, likely a consequence of the variant enzyme activity that results in a higher Hcy concentration and consequently higher MMA concentrations.

The SLC19A1 gene encodes an enzyme that participates in folic acid absorption, transporting for 5methylTHF, an important determinant of folate concentration, to the interior of a variety of cells $[50,52]$. The SLC19A1 gene is polymorphic at nucleotide $80(\mathrm{~A}>\mathrm{G})$, and an assessment of the impact of this polymorphism on protein function has demonstrated a difference in its affinity for subtracts and/or its efficiency in transport compared to the wild type enzyme [24]. Chango et al. [1] observed that SLC19A1 c.80AA/ MTHFR c.677CT individuals exhibited higher plasma folate levels than SLC19A1 c.80GG/ MTHFR c.677CT individuals, which corroborates our observations of lower folate concentrations in the presence of the SLC19A1 c.80 GG genotype.

Because most polymorphisms, with the exception of $C B S$ c.844ins68 and c.833 T>C, did not deviate from the HW equilibrium, our sample set was appropriately ascertained [18,19]. Departure from the HW equilibrium may have resulted from random selection or a small sample size.

A major strength of our study was the number of polymorphisms in folate metabolism genes investigated. Out of 12 polymorphisms, five have never been analyzed in a Brazilian population until now, including the $B H M T$ c. $742 \mathrm{G}>\mathrm{A}$ and $T C N 2$ c. $67 \mathrm{~A}>\mathrm{G}$ polymorphisms that influence the maternal risk for DS. A potential limitation of our study is that folate and MMA concentrations were not measured at the child's delivery in both case and control mothers. Although the measurement of the concentrations at the time of conception would have been more relevant, the current quantification is a likely reflection of adult dietary patterns, once an adult's dietary tends to have a similar pattern over the time. Also, the influence of the polymorphisms on MMA and folate concentrations was analyzed in the total group, including DS and control mothers, to investigate the polymorphism influence on the concentrations regardless of the presence of a DS child. The small size of the case group, which could reduce the power of the statistical analysis and complicate an investigation 


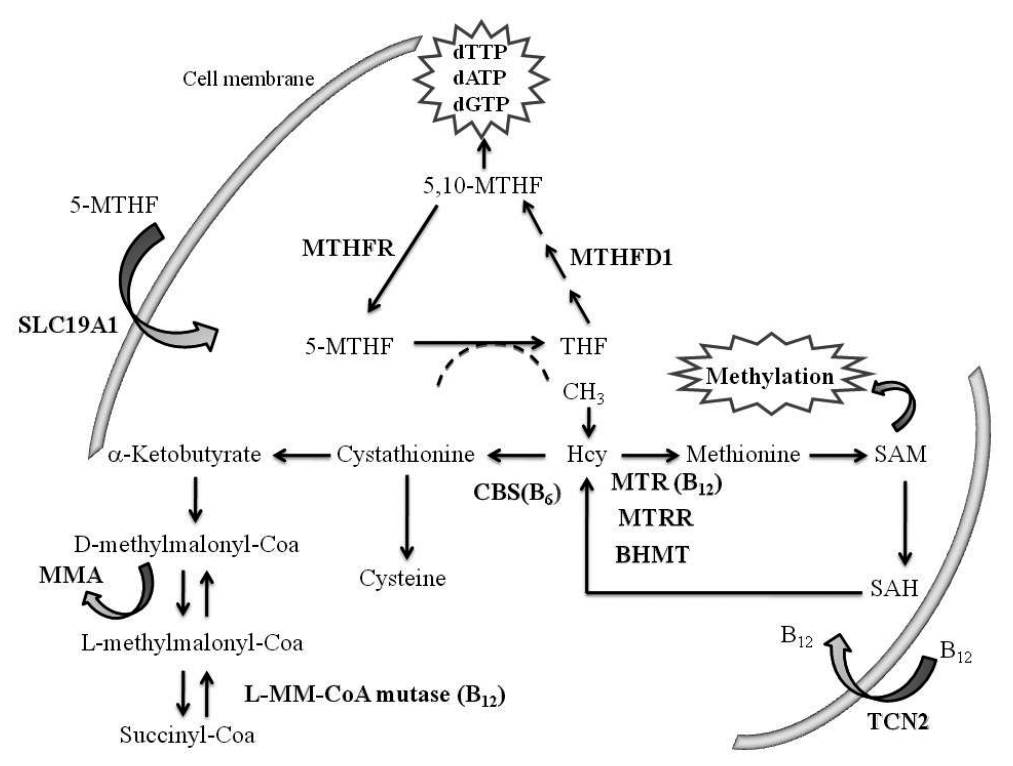

Fig. 1. Folate metabolism. BHMT $=$ betaine-homocysteine S-methyltransferase; $\mathrm{CBS}=$ cystathionine-beta-synthase; $\mathrm{CH}_{3}=$ methyl, 5,10-MTHF $=5,10$-methylenetetrahydrofolate, 5 -MTHF $=5$-methyltetrahydrofolate; dATP $=$ deoxyadenosine 5 '-triphosphate; dGTP $=$ deoxyguanosine 5'-triphosphate; dTTP = deoxythymidine 5'-triphosphate; Hcy = homocysteine; MMA = methylmalonic acid; MTHFD1 = methylenetetrahydrofolate dehydrogenase (NADP+ dependent) 1, methenyltetrahydrofolate cyclohydrolase, formyltetrahydrofolate synthetase ; MTHFR = methylenetetrahydrofolate reductase $(\mathrm{NAD}(\mathrm{P}) \mathrm{H}) ; \mathrm{MTR}=5$-methyltetrahydrofolate-homocysteine methyltransferase; MTRR $=$ 5-methyltetrahydrofolate-homocysteine methyltransferase reductase; SLC19A1 = solute carrier family 19 (folate transporter), member 1; SAH = S-adenosyl-homocysteine; SAM $=$ S-adenosylmethionine; $\mathrm{TCN} 2=$ transcobalamin II; THF $=$ tetrahydrofolate.

of possible genotype combinations that may influence the maternal risk for DS, was an additional limitation of this study. However, studies that have investigated an association between folate gene polymorphisms and the risk of DS offspring have been conducted with relatively small sample sizes [9], primarily due to difficulties in the recruitment of these mothers, with significant results.

In conclusion, the results of this study indicate that the TCN2 c.776C>G, BHMT c.742A $>\mathrm{G}$, and $M T H-$ FR c. $677 \mathrm{C}>\mathrm{T}$ polymorphisms and the MTHFR $677 \mathrm{C}$ 1298A-1317T haplotype modulate the risk for DS. The polymorphisms MTHFR c.677C $>$ T and SLC19A1 c.80 A $>\mathrm{G}$ modulate folate concentrations, whereas the MTRR c.66A $>\mathrm{G}$ polymorphism affects MMA concentrations. These findings contribute to future research aimed at identifying metabolic interventions that will aid in preventing nondisjunction of the 21 chromosome. Future studies may benefit from sample sizes that are large enough to identify specific gene-gene interactions.

\section{Acknowledgments}

The authors are grateful to the mothers that participated in this study, to the Prof. Dr. Moacir F. Godoy for his help, to the Ding-Down workgroup (multidisciplinary group of health professionals - FAMERP) and to the FAMERP/FUNFARME for their collaboration in this work.

This study was supported by the FAPESP, CAPES and $\mathrm{CNPq}$.

\section{References}

[1] A. Chango, N. Emery-Fillon, G.P. de Courcy, D. Lambert, M. Pfister, D.S. Rosenblatt and J.P. Nicolas, A polymorphism $(80 \mathrm{G}>\mathrm{A})$ in the reduced folate carrier gene and its associations with folate status and homocysteinemia, Mol Genet Metab 70 (2000), 310-315.

[2] A. Mostowska, K.K. Hozyasz, P. Wojcicki, M. Dziegelewska and P.P. Jagodzinski, Associations of folate and choline metabolism gene polymorphisms with orofacial clefts, $J$ Med Genet 47(12) (2010), 809-815.

[3] A.P. Brandalize, E. Bandinelli, P.A. Dos Santos and L. SchülerFaccini, Maternal gene polymorphisms involved in folate metabolism as risk factors for Down syndrome offspring in Southern Brazil, Dis Markers 29(2) (2010), 95-101.

[4] B.D.F. Guenther, C.A. Sheppard, P. Tran, R. Rozen, R.G. Matthews and M.L. Ludwig, The structure and properties of methylenetetrahydrofolate reductase from Escherichia coli suggest how folate ameliorates human hyperhomocysteinemia, Nat Struct Biol 6 (1999), 359-365.

[5] C.A. Hobbs, S.L. Sherman, P. Yi, S.E. Hopkins, C.P. Torfs, R.J. Hine, M. Pogribna, R. Rozen and S.J. James, Polymorphisms 
in genes involved in folate metabolism as maternal risk factors for Down syndrome, Am J Hum Genet 67 (2000), 623-630.

[6] E. Pozzi, P. Vergani, L. Dalprà, R. Combi, D. Silvestri, F. Crosti, M. Dell'Orto and M.G. Valsecchi, Maternal polymorphisms for methyltetrahydrofolate reductase and methionine synthetase reductase and risk of children with Down syndrome, Am J Obstet Gynecol 200(6) (2009), 636.e1-636.e6.

[7] E.G. Allen, S.B. Freeman, C. Druschel, C.A. Hobbs, L.A. O'Leary, P.A. Romitti, M.H. Royle, C.P. Torfs and S.L. Sherman, Maternal age and risk for trisomy 21 assessed by the origin of chromosome nondisjunction: a report from the Atlanta and National Down Syndrome Projects, Hum Genet 125 (2009), 41-52.

[8] F. Coppedè, F. Migheli, S. Bargagna, G. Siciliano, I. Antonucci, L. Stuppia, G. Palka and L. Migliore, Association of maternal polymorphisms in folate metabolizing genes with chromosome damageand risk of Down syndrome offspring, Neurosci Lett 449 (2009), 15-19.

[9] F. Coppedè, The complex relationship between folate/homocysteine metabolism and risk of Down syndrome, Mutat Res 682(1) (2009), 54-70.

[10] F. Li, Q. Feng, C. Lee, S. Wang, L.L. Pelleymounter, I. Moon, B.W. Eckloff, E.D. Wieben, D.J. Schaid, V. Yee and R.M. Weinshilboum, Human betaine-homocysteine methyltransferase (BHMT) and BHMT2: common gene sequence variation and functional characterization, Mol Genet Metab 94 (2008), 326-335.

[11] F.A. Hol, N.M.J. van der Put, M.P.A. Geurds and H.J. Blom, Molecular genetic analysis of the gene encoding the trifunctional

enzyme MTHFD (methylenetetrahydrofolate-dehydrogenase, methenyltetrahydrofolate-cyclohydrolase, formyltetrahydrofolate synthetase) in patients with neural tube defects, Clin Genet 53 (1998), 119-125.

[12] F.C. Parra, R.C. Amado, J.R. Lambertucci, J. Rocha, C.M Antunes and S.D. Pena, Color and genomic ancestry in Brazilians, Proc Natl Acad Sci USA 100 (2003), 177-182.

[13] G. Barkai, S. Arbuzova, M. Berkenstadt, S. Heifetz and H. Cuckle, Frequency of Down's syndrome and neural tube defects in the same family, Lancet 361(9366) (2003), 13311335.

[14] H. Gellekink, H.J. Blom, I.J. van der Linden and M. den Heijer, Molecular genetic analysis of the human dihydrofolate reductase gene: relation with plasma total homocysteine, serum and red blood cell folate levels, Eur J Hum Genet 15(1) (2007), 103-109.

[15] H. Olteanu, T. Munson and R. Banerjee, Differences in the efficiency of reductive activation of methionine synthase and exogenous electron acceptors between the common polymorphic variants of human methionine synthase reductase, Biochemistry 41(45) (2002), 13378-13385.

[16] I. Morin, R. Platt, I. Weisberg, N. Sabbaghian, Q. Wu, T.A. Garrow and R. Rozen, Common variant in betainehomocysteine methyltransferase (BHMT) and risk for spina bifida, Am J Med Genet 119A(2) (2003), 172-176.

[17] I. Scala, B. Granese, M. Sellitto, S. Salomè, A. Sammartino, A. Pepe, P. Mastroiacovo, G. Sebastio and G. Andria, Analysis of seven maternal polymorphisms of genes involved in homocysteine/folate metabolism and risk of Down syndrome offspring, Genet Med 8(7) (2006), 409-416.

[18] J. Wittke-Thompson, A. Pluzhnikov and N.J. Cox, Rational inferences about departures from hardy-Weinberg equilibrium, Am J Hum Genet 76 (2005), 967-986.
[19] J. Xu, A. Turner, J. Little, E.R. Bleecker and D.A. Meyers, Positive results in association studies are associated with departure from Hardy- Weinberg equilibrium: hint for genotyping error? Hum Genet 111(6) (2002), 573-574.

[20] J.J. Pietrzyk and M. Bik-Multanowski, 776C>G polymorphism of the transcobalamin II gene as a risk factor for spina bifida, Mol Genet Metab 80 (2003), 364.

[21] J.M. Biselli, D. Brumati, V.F. Frigeri, B.L. Zampieri, E.M. Goloni-Bertollo and E.C. Pavarino-Bertelli, A80G polymorphism of reduced folate carrier 1 (RFC1) and $\mathrm{C} 776 \mathrm{G}$ polymorphism of transcobalamin 2 (TCN2) genes in Down's syndrome etiology, São Paulo Med J 126(6) (2008), 329-332.

[22] J.M. Biselli, E.M. Goloni-Bertollo, B.L. Zampieri, R. Haddad, M.N. Eberlin and E.C. Pavarino-Bertelli, Genetic polymorphisms involved in folate metabolism and elevated concentrations of plasma homocysteine: maternal risk factors for Down syndrome in Brazil, Genet Mol Res 7 (2008), 33-42.

[23] J.M. Biselli, E.M. Goloni-Bertollo, R. Haddad, M.N. Eberlin and E.C. Pavarino-Bertelli, The MTR A2756G polymorphism is associated with an increase of plasma homocysteine concentration in Brazilian individuals with Down syndrome, Braz J Med Biol Res 41(1) (2008), 34-40.

[24] J.R. Whetstine, A.J. Gifford, T. Witt, X.Y. Liu, R.M. Flatley, M. Norris, M. Haber, J.W. Taub, Y. Ravindranath and L.H. Matherly, Single nucleotide polymorphisms in the human reduced folate carrier: characterization of a high-frequency G/A variant at position 80 and transport properties of the His(27) and $\operatorname{Arg}(27)$ carriers, Clinical Cancer Research: An Official Journal of the American Association for Cancer Research 7(11) (2001), 3416-3422.

[25] K. Yamada, Z. Chen, R. Rozen and R.G. Matthews, Effects of common polymorphisms on the properties of recombinant human methylenetetrahydrofolate reductase, Proc Natl Acad Sci U S A 8(26) (2001), 14853-14858.

[26] K.J.A. Lievers, L.A. Afman and L.A.J. Kluijtmans, Polymorphisms in the Transcobalamin Gene: Association with Plasma Homocysteine in Healthy Individuals and Vascular Disease Patients, Clin Chem 48(9) (2002), 1383-1389.

[27] K.L. Jones, Smith's Recognizable Patterns of Human Malformation, (6th ed.), Philadelphia: Elsevier Saunders, 2006.

[28] K.M. von Castel-Dunwoody, G.P. Kauwell, K.P. Shelnutt, J.D. Vaughn, E.R. Griffin, D.R. Maneval, D.W. Theriaque and L.B. Bailey, Transcobalamin 776C->G polymorphism negatively affects vitamin B-12 metabolism, Am J Clin Nutr 81(6) (2005), 1436-1441.

[29] K.R. Wolthers and N.S. Scrutton, Protein interactions in the human methionine synthase-methionine synthase reductase complex and implications for the mechanism of enzyme reactivation, Biochemistry 46 (2007), 6696-6709.

[30] L. DeVos, A. Chanson, Z. Liu, E.D. Ciappio, L.D. Parnell, J.B. Mason, K.L.Tucker and J.W. Crott, Associations between single nucleotide polymorphisms in folate uptake and metabolizing genes with blood folate, homocysteine, and DNA uracil concentrations, Am J Clin Nutr 88(4) (2008), 1149-1158.

[31] L. Migliore, G. Boni, R. Bernardini, F. Trippi, R. Colognato, I. Fontana, F. Coppedè and I. Sbrana, Susceptibility to chromosome malsegregation in lymphocytes of women who had a Down syndrome child in young age, Neurobiol Aging 27(5) (2006), 710-716.

[32] L.R. da Silva, N. Vergani, C. Galdieri Lde, M.P. Ribeiro Porto, S.B. Longhitano, D. Brunoni, V. D'Almeida and A.B. Alvarez Perez, Relationship Between Polymorphisms in Genes Involved in Homocysteine Metabolism and Maternal Risk for 
Down Syndrome in Brazil, Am J Med Genet 135A(3) (2005), 263-267.

[33] M. Födinger, J. Dierkes, S. Skoupy, C. Röhrer, W. Hagen, H. Puttinger, A.C. Hauser, A. Vychytil and G. Sunder-Plassmann, Effect of glutamate carboxypeptidase II and reduced folate carrier polymorphisms on folate and total homocysteine concentrations in dialysis patients, J Am Soc Nephrol 14(5) (2003), 1314-1319.

[34] M. Shi, D.Caprau, P. Romitti, K. Christensen and J.C. Murray, Genotype frequencies and linkage disequilibrium in the CEPH human diversity panel for variants in folate pathway genes MTHFR, MTHFD, MTRR, RFC1, and GCP2, Birth Defects Res A Clin Mol Teratol 67 (2003), 545-549.

[35] M.F. Sadiq, E.A. Al-Refai, A. Al-Nasser, M. Khassawneh and Q. Al-Batayneh, Methylenetetrahydrofolate reductase polymorphisms C677T and A1298C as maternal risk factors for Down syndrome in Jordan, Genet Test Mol Biomarkers 15(12) (2011), 51-57.

[36] M.L. Martínez-Frías, B. Pérez, L.R. Desviat, M. Castro, F. Leal, L. Rodrıguez, E. Mansilla, M.L. Martínez-Fernández, E. Bermejo, E. Rodríguez-Pinilla, D. Prieto and M. Ugarte, ECEMC Working Group, Maternal polymorphisms 677C-T and 1298A-C of MTHFR, and 66A-G MTRR genes: is there any relationship between polymorphisms of the folate pathway, maternal homocysteine levels, and the risk for having a child with Down syndrome? Am J Med Genet A 140 (2006), 987-997.

[37] M.P.S. Alvarenga, E.C. Pavarino-Bertelli and E.M. GoloniBertollo, Comparing Techniques for the Identification of the MTHFR A1298C, J Biomol Tech 19(2) (2008), 103-105.

[38] N. Fintelman-Rodrigues, J.C. Corrêa, J.M. Santos, M.M. Pimentel and C.B. Santos-Rebouças, Investigation of CBS, MTR, RFC-1 and TC polymorphisms as maternal risk factors for Down syndrome, Dis Markers 26(4) (2009), 155-161.

[39] N.A. Meguid, A.A. Dardir, M. Khass, L.E. Hossieny, A. Ezzat and M.K. El Awady, MTHFR genetic polymorphism as a risk factor in Egyptian mothers with Down syndrome children, Dis Markers 24(1) (2008), 19-26.

[40] P. Bosco, R.M. Gueant-Rodriguez, G. Anello, C. Barone, F. Namour, F. Caraci, A. Roman, C. Romano and J.L. Gueant, Methionine synthase (MTR) $2756(\mathrm{~A}>\mathrm{G})$ polymorphism, double heterozygosity methionine synthase 2756 $\mathrm{AG} /$ methionine synthase reductase (MTRR) $66 \mathrm{AG}$, and elevated homocysteinemia are three risk factors for having a child with Down syndrome, Am J Med Genet A 121 (2003), 219-224.

[41] P. Frosst, H.J. Blom, R. Milos, P. Goyette, C.A. Sheppard, R.G. Matthews, G.J.H. Boers, M. den Heijer, L.A.J. Kluijtmans, L.P. van den Heuve and R. Rozen, A candidate genetic risk factor for vascular disease: a common mutation in Methylenetetrahydrofolate reductase, Nat Genet 10(1) (1995), 111-113.
[42] P.M. Ueland, HCholine and betaine in health and disease, $H J$ Inherit Metab Dis 34(1) (2011), 3-15.

[43] P.R. Barbosa, S.P. Stabler, R. Trentin, F.R. Carvalho, A.D. Luchessi, Hirata R.D., M.H. Hirata, R.H. Allen and E.M. Guerra-Shinohara, Evaluation of nutritional and genetic determinants of total homocysteine, methylmalonic acid and S-adenosylmethionine/S-adenosylhomocysteine values in Brazilian childbearing-age women, Clinica Chimica Acta 388(1-2) (2008), 139-147.

[44] Q.H. Yang, L.D. Botto, M. Gallagher, J.M. Friedman, C.L. Sanders, D. Koontz, S. Nikolova, J.D. Erickson and K. Steinberg, Prevalence and effects of gene-gene and gene-nutrient interactions on serum folate and serum total homocysteine concentrations in the United States: findings from the third National Health and Nutrition Examination Survey DNA Bank, Am J Clin Nutr 88 (2008), 232-246.

[45] S. Beetstra, P. Thomas, C. Salisbury, J. Turner and M. Fenech, Folic acid deficiency increases chromosomal instability, chromosome 21 aneuploidy and sensitivity to radiation-induced micronuclei, Mutat Res 578 (2005), 317-326.

[46] S.A. Miller, D.D. Dykes and H.F. Polesky, A simple salting out procedure for extracting DNA from human nucleated cells, Nucleic Acids Res 16(3) (1988), 1215.

[47] S.J. James, I.P. Pogribny, M. Pogribna, B.J. Miller, S. Jernigan and S. Melnyk, Mechanisms of DNA damage, DNA hypomethylation, and tumor progression in the folate/methyldeficient rat model of hepatocarcinogenesis, J Nutr 133 (2003), 3740S-37407S.

[48] S.J. James, M. Pogribna, I.P. Pogribny, S. Melnyk, R.J. Hine, J.B. Gibson, P. Yi, D.L. Tafoya, D.H. Swenson, V.L. Wilson and D.W. Gaylor, Abnormal folate metabolism and mutation in the methylenetetrahydrofolate reductase gene may be maternal risk factors for Down syndrome, Am J Clin Nutr 70(4) (1999), 495-501.

[49] S.S. Wang, F.Y. Qiao, L. Feng and J.J. Lv, Polymorphisms in genes involved in folate metabolism as maternal risk factors for Down syndrome in China, $J$ Zhejiang Univ Sci B 9(2) (2008), 93-99.

[50] T.T. Nguyen, D.L. Dyer, D.D. Dunning, S.A. Rubin, K.E. Grant and H.M. Said, Human intestinal folate transport: cloning, expression, and distribution of complementary RNA, Gastroenterology 112(3) (1997), 783-791.

[51] V.M. Carvalho and F. Kok, Determination of serum methylmalonic acid by alkylative extraction and liquid chromatography coupled to tandem mass spectrometry, Anal Biochem $\mathbf{3 8 1}$ (2008), 67-73.

[52] Z. Hou and L.H. Matherly, Oligomeric structure of the human reduced folate carrier: identification of homo-oligomers and dominant-negative effects on carrier expression and function, J Biol Chem 284 (2009), 3285-3293. 


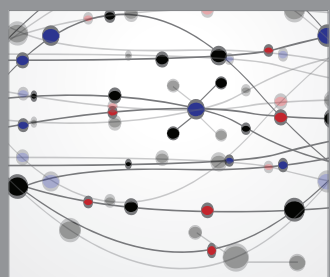

The Scientific World Journal
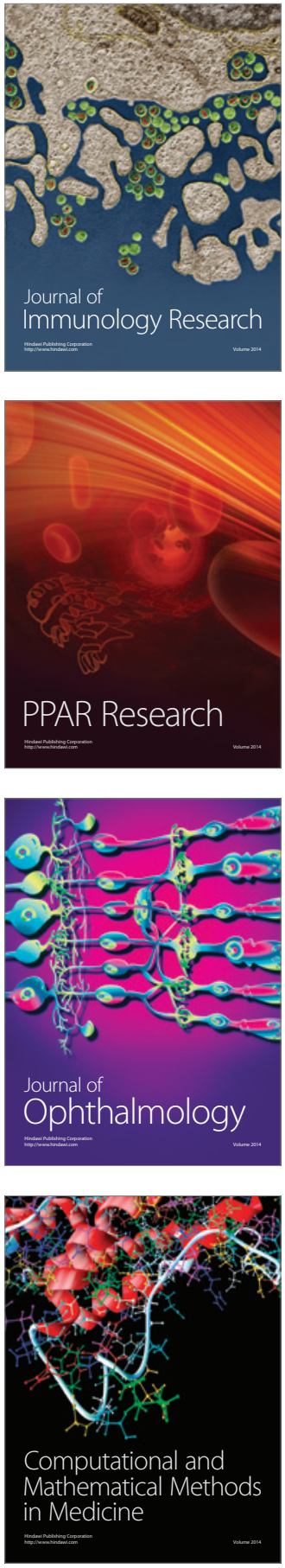

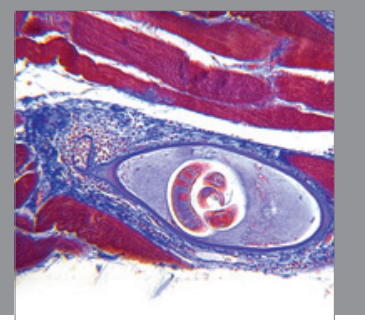

Gastroenterology

Research and Practice
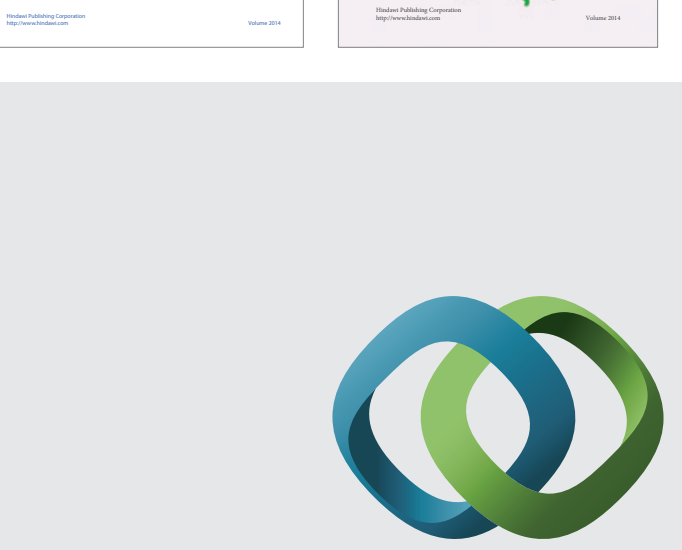

\section{Hindawi}

Submit your manuscripts at

http://www.hindawi.com
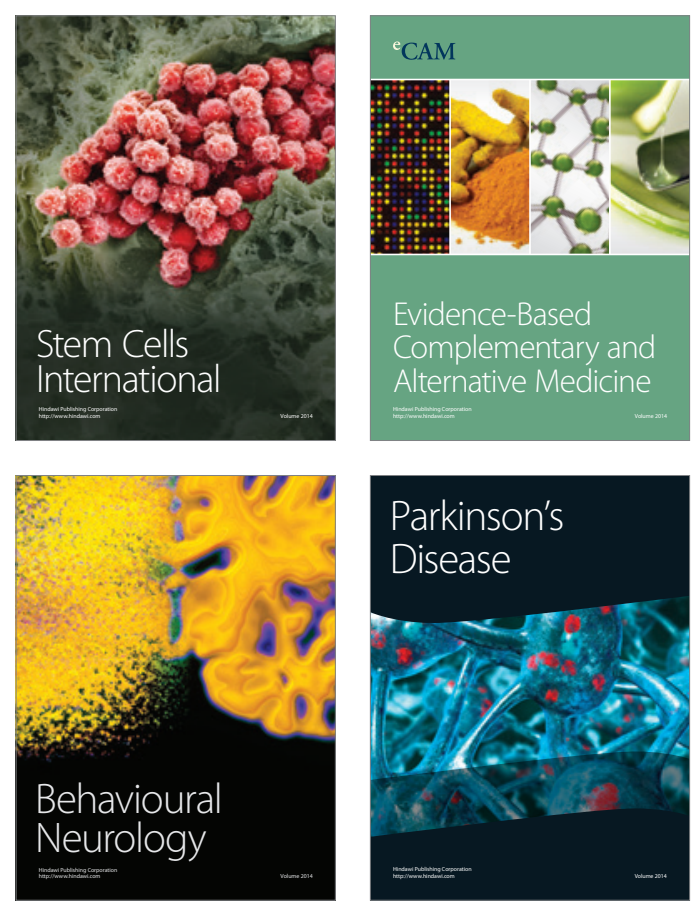

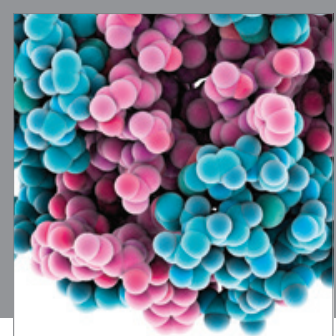

Journal of
Diabetes Research

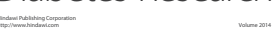

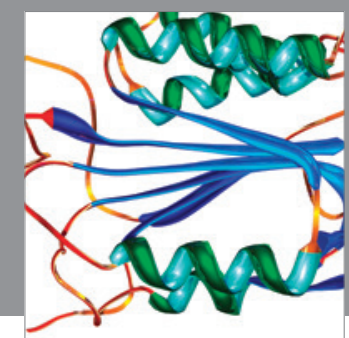

Disease Markers
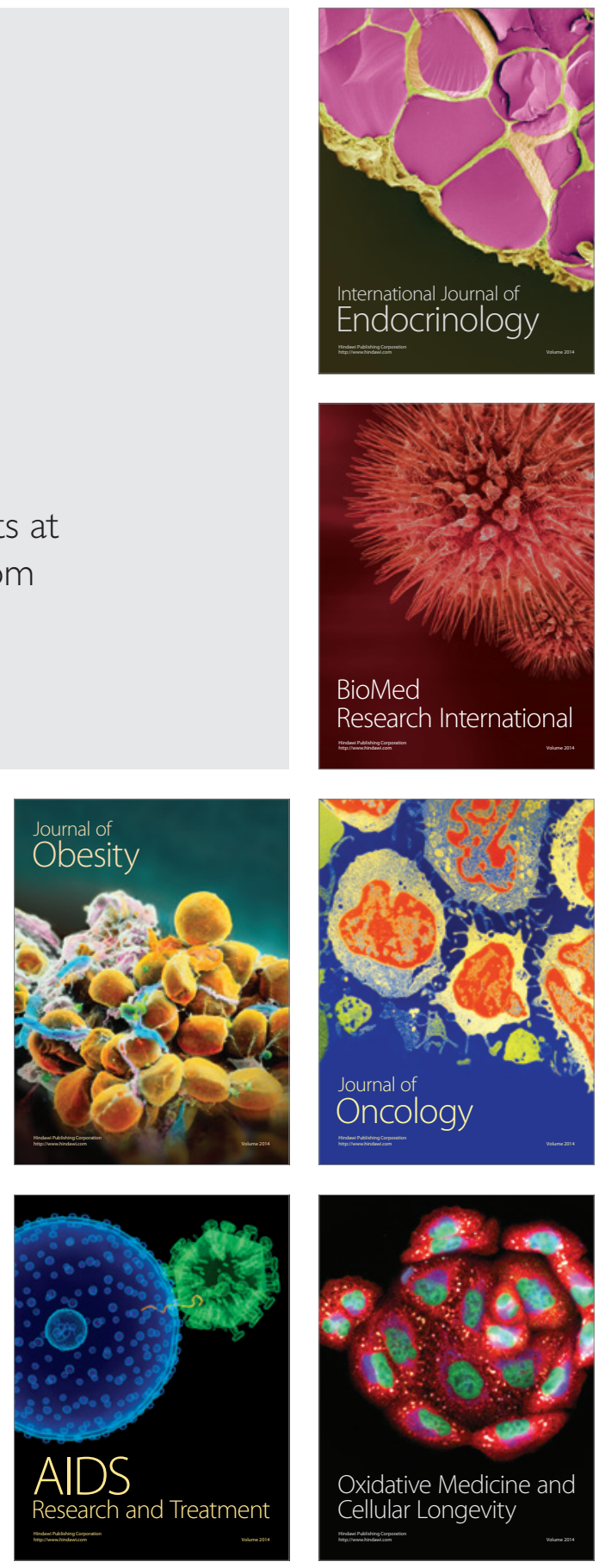